\title{
Current approaches to the diagnosis, treatment, and reporting of trichomoniasis and candidosis
}

\author{
B. H. O'CONNOR* AND M. W. ADLER \\ From the Academic Department of Genitourinary Medicine, Middlesex Hospital Medical School, London
}

SUMMARY The current approach to the management of trichomoniasis and candidosis in sexually transmitted disease (STD) clinics in England and Wales is described. Microscopy alone was used in the diagnosis of trichomoniasis in $44 \%$ of clinics and of candidosis in $35 \%$ of clinics. Oral metronidazole was used for the treatment of trichomoniasis in women in $92 \%$ of clinics. Vaginal pessaries containing nystatin or clotrimazole were routinely used to treat candidosis in $95 \%$ of clinics. Male sexual contacts of female patients with candidosis and trichomoniasis were invited to attend for examination in $88 \%$ of clinics. Physicians in $81 \%$ of clinics prescribed treatment on epidemiological grounds for male contacts of female patients with trichomoniasis. A more uniform approach to the diagnostic categories used for the quarterly returns for cases treated epidemiologically is recommended.

\section{Introduction}

Trichomoniasis and candidosis rarely exhibit the more serious consequences associated with some of the other sexually transmitted diseases (STDs). The two conditions, however, are common and together account for nearly as many notified cases as does gonorrhoea (Department of Health and Social Security, 1976).

Previous papers in this series have described a survey of the facilities and services provided by STD clinics in England and Wales (Adler et al., 1978a), and the diagnosis, treatment, and notification of certain diseases, including gonorrhoea (Adler, $1978 \mathrm{~b}, \mathrm{c}$ ), herpes genitalis (Belsey and Adler, 1978), and non-specific genital infection (Adler, 1978d, e).

This paper describes the current approach to the management of trichomoniasis and candidosis by physicians working in 173 clinics for female patients and in 171 clinics for male patients.

\section{Results}

\section{TRICHOMONIASIS}

\section{Diagnosis}

Physicians working in $77(44 \%)$ clinics diagnosed trichomoniasis in female patients by microscopical

*Present address: Camden and Islington Area Health Authority (Teaching)

Address for reprints: Professor M. W. Adler, Academic Department of Genitourinary Medicine, Middlesex Hospital Medical School, London W1N 8AA

Received for publication 29 June 1978 examination of vaginal secretions alone. In a further $93(54 \%)$ clinics, cultures of vaginal samples were also used, and finally in three clinics cultures were used alone. The commonest culture medium used was Feinberg-Whittington medium, or one of its modifications (in 69 clinics, $72 \%$ of those using cultures).

Although physicians in all clinics had access to a microscopy service, in eight clinics the specimens for trichomoniasis had to be sent to a central laboratory and the results were not available at the patient's initial attendance. Treatment was instituted on the basis of the history and clinical findings by physicians in six of these clinics and in one where the clinical history and examination was suggestive of salpingitis. In one clinic treatment was given only after positive microscopical examination results were received from the laboratory.

\section{Examination of male contacts}

Physicians in 150 clinics $(88 \%$ of those seeing male patients) attempted to see male sexual contacts of women with trichomoniasis; in 112 clinics this was routine practice for all contacts. In the remaining 38 clinics sexual contacts were seen in only selected instances, the commonest reasons being that the woman had recurrent attacks of trichomoniasis, that the man was the regular sexual partner, or that the man had symptoms.

Male contacts of female patients with trichomoniasis may be asymptomatic and may have no 
urethral discharge on examination. In $126(84 \%)$ of the 150 clinics where sexual contacts were examined physicians used a variety of methods to collect specimens in these circumstances. The most common method was to perform a urethral scrape (Table 1). Specimens were collected by one method only in 68 clinics, by two methods in 37 clinics, and by three or more methods in 15 clinics. Physicians working in 24 clinics did not take specimens for laboratory examination.

Table 1 Methods of obtaining specimens from asymptomatic male contacts of female patients with trichomoniasis

\begin{tabular}{llc}
\hline Method & \multicolumn{2}{l}{ Clinics $(n=126)$} \\
\cline { 2 - 3 } & No. & $\%$ \\
\hline Urethral scrape & 105 & $83 \cdot 3$ \\
Prostatic smear & 32 & $25 \cdot 4$ \\
Specimen of centrifuged urine & 28 & $22 \cdot 2$ \\
Early morning smear & 15 & $11 \cdot 9$ \\
Threads from two-glass urine test & 10 & $7 \cdot 9$ \\
Other & 1 & $0 \cdot 8$ \\
Not known & 6 & $4 \cdot 8$ \\
\hline
\end{tabular}

\section{Epidemiological treatment}

In the survey epidemiological treatment was defined as treatment given to named sexual contacts after a history of exposure but without (or in advance of) confirmatory pathological findings. Physicians working in $138(81 \%)$ clinics were prepared to use this approach for male sexual contacts. In 122 clinics specimens were taken for laboratory examination: for microscopy in 58 clinics, for both microscopy and culture in 60 clinics, and for cultures alone in four clinics. In 16 clinics, physicians examined the male contact but did not carry out any investigations before prescribing treatment.

\section{Treatment by proxy}

In contrast to epidemiological treatment physicians in $79(46 \%)$ clinics prescribed treatment for a male contact in his absence and gave the female patient tablets for him. This constitutes treatment by proxy, which was used on all occasions by physicians working in 24 clinics and only occasionally in the remaining 55 clinics.

\section{Antimicrobial treatment for trichomoniasis}

The treatment usually prescribed for trichomoniasis was oral metronidazole; this was used in $160(92 \%)$ clinics for women and in $156(91 \%)$ clinics for men. The commonest regimens for female patients (Table 2) were $0.6 \mathrm{gm}$ daily for seven days (88 clinics) and $0.8 \mathrm{gm}$ daily for five days (26 clinics). In only seven clinics was this drug prescribed for
Table 2 Drugs used to treat trichomoniasis in women

\begin{tabular}{|c|c|c|c|c|c|c|}
\hline \multirow[b]{3}{*}{ Drugs (grams/day) } & \multicolumn{6}{|c|}{ Number of clinics } \\
\hline & \multicolumn{5}{|c|}{ Duration of treatment regimen (days) } & \multirow[b]{2}{*}{ Tota } \\
\hline & $1-1 \frac{1}{2}$ & $2-3$ & $5-6$ & 7 & 10 & \\
\hline \multicolumn{7}{|l|}{ Metronidazole } \\
\hline 0.4 & - & - & 1 & - & - & 1 \\
\hline $0 \cdot 6$ & - & - & 1 & 88 & 2 & 91 \\
\hline $0 \cdot 8$ & - & 5 & 26 & 11 & - & 42 \\
\hline $1 \cdot 2$ & 2 & - & - & 2 & 5 & 9 \\
\hline $1 \cdot 6$ & - & 7 & - & - & - & 7 \\
\hline $2 \cdot 0$ & 9 & 1 & - & - & - & 10 \\
\hline Total no. of clinics & 11 & 13 & 28 & 101 & 7 & 160 \\
\hline \multicolumn{7}{|l|}{ Nimorazole } \\
\hline $1 \cdot 0$ & 3 & 3 & - & - & - & 6 \\
\hline $2 \cdot 0$ & 6 & - & - & - & - & 6 \\
\hline $2 \cdot 5$ & 1 & - & - & - & - & 1 \\
\hline Total no. of clinics & 10 & 3 & - & - & - & 13 \\
\hline
\end{tabular}

longer than seven days $-1 \cdot 2 \mathrm{gm}$ daily for 10 days (five clinics) and $0.6 \mathrm{gm}$ daily for 10 days (two clinics). The pattern of treatment for men was similar. Physicians working in 13 clinics for women and in $16(9 \%)$ clinics for men prescribed nimorazole, the most usual regimen being a single dose of $2 \mathrm{gm}$.

\section{Alcohol and treatment}

Consultants working in 111 and 108 clinics for male and female patients respectively advised patients not to drink alcohol during treatment. The reasons are shown in Table 3 ; the commonest reason given ( 70 clinics) was the possible disulfiramlike ('antabuse') effect with treatment. In 92 clinics physicians gave one reason, in 12 they gave two, and in five they gave three.

Table 3 Reasons given for asking patients to abstain from alcohol during treatment for trichomoniasis

\begin{tabular}{llc}
\hline & \multicolumn{2}{l}{ Clinics $(n=111)$} \\
\cline { 2 - 3 } Reasons given & $N o$. & $\%$ \\
\hline Disulfiram-like (antabuse) effect & 70 & $63 \cdot 1$ \\
Irritates urethra/exacerbates urethritis & 19 & $17 \cdot 1$ \\
Patients should remain sober & 19 & $17 \cdot 1$ \\
Delays drug absorption & 12 & $10 \cdot 8$ \\
Causes pelvic congestion & 5 & $4 \cdot 5$ \\
Standard practice & 4 & $3 \cdot 6$ \\
Causes relapse & 2 & $1 \cdot 8$ \\
Not known & 2 & $1 \cdot 8$ \\
\hline
\end{tabular}

\section{Follow-up investigations}

The pattern of follow-up investigations (Table 4) shows that physicians working in $128(74 \%)$ clinics for women and in $72(42 \%)$ clinics for men repeated investigations on two or more occasions. No follow up was carried out in seven clinics for women nor in 50 clinics for men. 
Table 4 Number of repeat investigations after treatment for trichomoniasis

\begin{tabular}{|c|c|c|c|c|}
\hline \multirow{3}{*}{$\begin{array}{l}\text { No. of repeat } \\
\text { investigations }\end{array}$} & \multicolumn{4}{|c|}{ Clinics } \\
\hline & \multicolumn{2}{|c|}{ For women } & \multicolumn{2}{|c|}{ For men } \\
\hline & No. & $\%$ & No. & $\%$ \\
\hline None & 7 & $4 \cdot 0$ & 50 & $29 \cdot 2$ \\
\hline One & 38 & $22 \cdot 0$ & 42 & $24 \cdot 6$ \\
\hline Two & 82 & $47 \cdot 4$ & 45 & $26 \cdot 3$ \\
\hline Three or more & 46 & $26 \cdot 6$ & 27 & $15 \cdot 8$ \\
\hline Not known & 0 & $0 \cdot 0$ & 7 & $4 \cdot 1$ \\
\hline Total & 173 & $100 \cdot 0$ & 171 & $100 \cdot 0$ \\
\hline
\end{tabular}

\section{Quarterly returns}

Consultants were asked to indicate the criteria which they used to make a return for a case of trichomoniasis to the Department of Health and Social Security (DHSS). All physicians using positive microscopical findings alone to make a diagnosis of trichomoniasis would use this as a basis for notification. In those clinics where microscopy and culture were both used, a case would be notified if either or both gave positive results. In eight clinics treatment was given in all or selected cases on clinical grounds alone. In three of the clinics a return would be made on the basis of the clinical diagnosis without supportive investigations.

Physicians treating male contacts epidemiologically or by proxy used different diagnostic categories. Table 5 shows the categories used when the smears or cultures or both gave negative results and the patient had either already been treated (cases treated epidemiologically) or had not been seen in the clinic (cases treated by proxy). Physicians working in 101 clinics notified the DHSS (Table 5) of male contacts treated epidemiologically as 'other conditions requiring treatment' (D2) and in 22 clinics as trichomoniasis (C6). Consultants in nine clinics notified male contacts treated by proxy

Table 5 Returns to the DHSS for male contacts treated for trichomoniasis in whom laboratory investigations gave negative results

\begin{tabular}{|c|c|c|c|c|}
\hline \multirow[b]{2}{*}{ Categories used in returns } & \multicolumn{2}{|c|}{$\begin{array}{l}\text { Cases treated } \\
\text { epidemiologically }\end{array}$} & \multicolumn{2}{|c|}{$\begin{array}{l}\text { Cases treated } \\
\text { by proxy }\end{array}$} \\
\hline & No. & $\%$ & No. & $\%$ \\
\hline $\begin{array}{l}\text { Trichomoniasis (C6) } \\
\text { Non-specific genital }\end{array}$ & 22 & $15 \cdot 9$ & 0 & 0.0 \\
\hline $\begin{array}{l}\text { infection }(\mathrm{C} 4) \\
\text { Other conditions requiring }\end{array}$ & 7 & $5 \cdot 1$ & $\mathbf{0}$ & $0 \cdot 0$ \\
\hline $\begin{array}{l}\text { treatment (D2) } \\
\text { Other conditions not }\end{array}$ & 101 & $73 \cdot 2$ & 7 & 8.9 \\
\hline $\begin{array}{l}\text { requiring treatment (D3) } \\
\text { No return } \\
\text { Not known } \\
\text { Total }\end{array}$ & $\begin{array}{r}8 \\
0 \\
0 \\
138\end{array}$ & $\begin{array}{r}5 \cdot 8 \\
0 \cdot 0 \\
0 \cdot 0 \\
100 \cdot 0\end{array}$ & $\begin{array}{r}2 \\
62 \\
8 \\
79\end{array}$ & $\begin{array}{r}2 \cdot 5 \\
78 \cdot 5 \\
10 \cdot 1 \\
100 \cdot 0\end{array}$ \\
\hline
\end{tabular}

either as 'other conditions requiring treatment' (D2) or as 'other conditions not requiring treatment' (D3). In most instances no return was made for cases treated by proxy.

\section{CANDIDOSIS}

\section{Diagnosis}

In $61(35 \%)$ clinics physicians made the diagnosis of candidosis in female patients on the basis of microscopical examination of vaginal secretions alone. In the remaining $112(65 \%)$ clinics cultures of vaginal material were also used, the commonest medium being Sabouraud's or one of its modifications (Table 6).

In nine clinics smear results were not available at the patient's first attendance, and physicians in seven of these clinics treated the patient for candidosis on the basis of clinical history and examination.

Table 6 Culture media used for diagnosis of candidosis

\begin{tabular}{lrr}
\hline & \multicolumn{2}{l}{ Clinics $(n=112)$} \\
\cline { 2 - 3 } Culture medium & No. & $\%$ \\
\hline Sabouraud or modification & 56 & $50 \cdot 0$ \\
Feinberg-Whittington or modification & 31 & $27 \cdot 7$ \\
Thayer-Martin or modification & 17 & $15 \cdot 2$ \\
Transport media & 2 & $1 \cdot 8$ \\
Other & 3 & $2 \cdot 7$ \\
Not known & 3 & $2 \cdot 7$ \\
Total & 112 & $100 \cdot 0$ \\
\hline
\end{tabular}

\section{Examination of male contacts}

In 150 clinics sexual contacts of female patients with candidosis were invited to attend-in all instances, in 49 clinics, or, in selected instances, in 101 clinics. The commonest reasons for selection (Table 7) were a history of symptoms in the male contact or recurrent attacks in the original female patient. One reason for selection was given in 74 clinics two in 25 clinics, and three in two clinics.

Table 7 Reasons given for examination of selected male contacts of female patients with candidosis

\begin{tabular}{llc}
\hline & \multicolumn{2}{l}{ Clinics $(\boldsymbol{n}=101)$} \\
\cline { 2 - 3 } Reasons given & No. & $\%$ \\
\hline History of symptoms in man & 78 & $77 \cdot 2$ \\
Recurrent attacks in woman & 36 & $35 \cdot 6$ \\
Regular partner & 9 & 8.9 \\
Patient's/contact's wish & 6 & $5 \cdot 9$ \\
Promiscuity of female partner & 1 & 1.0 \\
\hline
\end{tabular}




\section{Epidemiological treatment and treatment by proxy} Physicians in $56(33 \%)$ clinics used epidemiological treatment for male contacts, although in nine of these no investigations were carried out to establish the diagnosis. Treatment by proxy was the usual or occasional practice in $41(24 \%)$ clinics.

\section{Antifungal treatment}

The commonest form of treatment for candidosis was pessaries; these were used in $164(95 \%)$ clinics. Table 8 shows the types of pessaries and the regimens used; the most commonly used were nystatin - two a day for 14 to 15 days ( 32 clinics) - or clotrimazole-one daily for six to seven days (27 clinics). Miconazole pessaries were prescribed in nine clinics and hydrargaphen pessaries in three clinics.

Table 8 Number of clinics using pessaries to treat candidosis

\begin{tabular}{|c|c|c|c|c|c|}
\hline \multirow[b]{2}{*}{$\begin{array}{l}\text { Type of } \\
\text { pessary }\end{array}$} & \multirow{2}{*}{$\begin{array}{l}\text { Duration of } \\
\text { treatment } \\
(\text { days })\end{array}$} & \multicolumn{3}{|c|}{ Number of pessaries per day } & \multirow{2}{*}{$\begin{array}{l}\text { Total no. } \\
\text { of clinics } \\
(n=164)\end{array}$} \\
\hline & & One & Two & $\begin{array}{l}\text { Not } \\
\text { specified }\end{array}$ & \\
\hline \multicolumn{6}{|l|}{ Nystatin } \\
\hline & $6-7$ & 11 & 11 & 2 & 24 \\
\hline & 10 & 3 & 15 & 7 & 25 \\
\hline & 14-15 & 16 & 32 & 6 & 54 \\
\hline & $20-21$ & 3 & 0 & 2 & 5 \\
\hline \multirow{4}{*}{$\begin{array}{l}\text { Total no. of } \\
\text { clinics } \\
\text { Clotrimazole }\end{array}$} & & 33 & 58 & 17 & 108 \\
\hline & $6-7$ & 27 & 0 & 7 & 34 \\
\hline & 9 & 2 & 0 & 0 & 2 \\
\hline & 12 & 6 & 2 & 0 & 8 \\
\hline $\begin{array}{l}\text { Total no of } \\
\text { clinics }\end{array}$ & & 35 & 2 & 7 & 44 \\
\hline $\begin{array}{l}\text { Other } \\
\text { treatment }\end{array}$ & & & & & 12 \\
\hline
\end{tabular}

Most physicians did not treat every patient who was diagnosed as having candidosis. In $91(53 \%)$ clinics they were selective (Table 9). The commonest reasons for giving treatment in selected instances were that the patient had symptoms or signs. In 41 clinics one criterion for selection for treatment was given, in 40 two criteria were given, and in seven three or more were mentioned.

\section{Follow-up investigations and second treatment}

In $154(89 \%)$ clinics at least one follow-up investigation was carried out after treatment had been prescribed. If treatment appeared to have failed physicians in $137(79 \%)$ clinics prescribed a second course of pessaries; in 52 of these clinics a course of nystatin tablets was also prescribed.

Other measures were taken in some clinics if the patient appeared refractory to the first course of
Table 9 Reasons given for treatment selection of women with candidosis

\begin{tabular}{|c|c|c|}
\hline \multirow[b]{2}{*}{ Reasons given } & \multicolumn{2}{|c|}{ Clinics $(n=91)$} \\
\hline & No. & $\%$ \\
\hline Symptoms & 83 & $91 \cdot 2$ \\
\hline Signs & 23 & $25 \cdot 3$ \\
\hline Positive microscopical findings & 12 & $13 \cdot 2$ \\
\hline $\begin{array}{l}\text { Presence of candidosis might be masked by } \\
\text { other factors, such as pregnancy or anti- } \\
\text { biotic treatment }\end{array}$ & 10 & $11 \cdot 0$ \\
\hline $\begin{array}{l}\text { Positive microscopical evidence in the absence } \\
\text { of symptoms }\end{array}$ & 7 & $7 \cdot 7$ \\
\hline Symptoms in male consort & 5 & $5 \cdot 5$ \\
\hline Recurrent disease in female patient & 3 & $3 \cdot 3$ \\
\hline Anxiety in patient & 2 & $2 \cdot 2$ \\
\hline Not known & 3 & $3 \cdot 3$ \\
\hline
\end{tabular}

treatment: in 10 clinics diabetes mellitus was excluded and in three clinics a full medical examination was performed in an attempt to identify any predisposing factors. In five clinics, the patient was recommended to stop taking oral contraceptives.

\section{Quarterly returns}

In the 112 clinics where the diagnosis was made on the basis of both microscopical evidence and culture, a return was made for candidosis (C7) if they both gave positive results. Physicians in $104(93 \%)$ of these clinics would make a return of candidosis on the evidence of microscopy even if the culture results were negative; in $95(85 \%)$ of these clinics a return was made for candidosis if the results were negative on microscopical examination but positive on culture. In all clinics where microscopy was the only diagnostic criterion, microscopical evidence would be used as a basis for notification if the results were positive.

Physicians treating patients with candidosis on clinical evidence alone (seven clinics) reported all these as cases of candidosis. Of the physicians working in 56 clinics who treated patients epidemiologically, only those in six clinics recorded these as cases of candidosis. In the remaining $\mathbf{5 0}$ clinics such cases were included under the category of 'other conditions requiring treatment' (D2). In four clinics physicians would make returns for male contacts treated by proxy, in one clinic as candidosis (C7) and in three clinics as 'other conditions requiring treatment' (D2). In 27 clinics no returns were made in these instances. The type of return was not ascertained from physicians in 10 clinics.

Physicians were asked whether they made returns to the DHSS for all cases of candidosis. In 115 clinics each case diagnosed was returned but in 55 clinics returns included only cases which were both 
diagnosed and treated. In three clinics only cases in which candidosis was the principal diagnosis and had been treated were included in the returns.

\section{Discussion}

The diagnosis of trichomoniasis and candidosis depends on both clinical and laboratory examination. Feinberg and Whittington (1957) noted that trichomonads were detected in an additional $18 \%$ of vaginal specimens if culture techniques were used in association with microscopy. King and Nicol (1975) recommended the combination of smear and culture techniques as being more effective in establishing a diagnosis than either one alone. Recent work suggests that the diagnosis of candidosis may be missed more frequently than that of trichomoniasis if culture techniques are not used in combination with microscopy. Eddie (1968) showed that this could occur in up to $50 \%$ of cases, and Becker and Schweisfurth (1971) reported that $60 \%$ of candidal infections would be missed if microscopy was used alone. It has been suggested (Oriel, 1977) that culture of specimens is essential for a definitive diagnosis. Physicians working in $44 \%$ and $35 \%$ of clinics made the diagnosis of trichomoniasis and of candidosis respectively on microscopy alone; thus the use of culture techniques in addition to microscopy is suggested. Physicians working in seven clinics treated trichomoniasis and candidosis without any confirmatory microscopical or cultural evidence, a course of action which presupposes that it is possible to differentiate between these two diagnoses on macroscopical evidence alone and exclude other coexisting STDs. This is unlikely, and the use of some confirmatory laboratory procedures (microscopy or culture or both) is essential.

A distinction exists between the asymptomatic individual who is carrying Candida albicans as a commensal, but is free from clinical disease, and the patient with symptoms and signs who has a clinical, parasitic infestation with $C$. albicans (Oriel, 1977). The criteria for this differentiation into commensalism or parasitism are poorly defined (Ridley 1976), and some clinicians consider that symptoms are an unreliable guide to diagnosis (Morton and Rashid, 1977). In our survey some physicians did not treat patients with candidosis even though it had been diagnosed. A few physicians felt that positive microscopical evidence was a suitable indication for treatment, although in the absence of symptoms and signs in such cases the organism could be considered saprophytic and was not treated by others of their colleagues.
The widespread use by physicians of epidemiological treatment for trichomoniasis partly reflects the difficulty of making a diagnosis in the male contact. Watt and Jennison (1960) investigated a group of male patients whose female partners had intractable trichomoniasis and found that the majority in whom cultures gave positive results were asymptomatic. In the present survey specimens from asymptomatic male contacts were collected in most clinics, a practice which might usefully be extended to the remaining clinics to assist in the diagnosis of trichomoniasis in the male contact.

Treatment by proxy-in which the female patient is given tablets for her male partner-obviously prevents any diagnosis or exclusion of the disease (because the male contact remains unexamined). Tsao (1969) noted in a series of patients that the proportion of women diagnosed as having trichomoniasis who also had Neisseria gonorrhoeae in their microscopy or culture specimens was $46 \%$; recent reports have drawn attention to asymptomatic gonorrhoea in men (Portnoy et al., 1974; Handsfield et al., 1974). The taking of specimens from sexual contacts of women with trichomoniasis for laboratory examination is, therefore, important in making a full assessment in both partners. Any possibility of investigating a contact should not be lost, and the practice of giving treatment to patients who have not been seen by a doctor-and who are, therefore, not shown to be suffering from a disease and who might be affected by another concurrent STD-should be discouraged.

Metronidazole selectively inhibits parts of the alcohol detoxification pathway and has, therefore, a therapeutic role in the treatment of alcoholism in combination with disulfiram ('antabuse') (Rothstein and Clancy, 1969) or alone (Madalena and de Mattos, 1967). This metabolic interaction, which causes nausea and dizziness, is an important and uncomfortable side effect when patients receiving metronidazole take alcohol. Physicians in $60 \%$ of clinics did not specifically mention this to the patient. If these side effects appear without warning the patient may consider his reaction to the drug to be idiosyncratic and therefore stop his course of treatment.

Male contacts of women with trichomoniasis or candidosis treated epidemiologically in many clinics are usually notified to the DHSS as 'other conditions requiring treatment' (D2). Physicians recorded a definitive diagnosis of trichomoniasis (C6) and candidosis (C7) on a presumptive contact history alone without subsequent laboratory confirmation in 22 and six clinics respectively. The situation is further complicated by the inclusion in DHSS statistical results of cases of trichomoniasis and 
candidosis which have been diagnosed on clinical evidence alone. In addition, physicians working in nine clinics made returns to the DHSS for sexual contacts of trichomoniasis treated by proxy (D2 or D3) and in four for contacts of candidosis. Categorisation in these ways will alter the picture of the true size of the problem. This underlines the necessity for standardisation of the returns by agreement concerning diagnostic criteria, by the indication of cases treated epidemiologically as a separate category, and by the exclusion from returns of individuals who do not attend the clinic.

This study was supported as part of a project grant from the Medical Research Council. We thank Miss E. M. Belsey for statistical assistance. We are most grateful to Dr R. D. Catterall and Professor D. L. Miller for their encouragement, support, and comments.

\section{References}

Adler, M. W., Belsey, E. M., O'Connor, B. H., Catterall, R. D., and Miller, D. L. (1978a). Facilities and diagnostic criteria in sexually transmitted diseases clinics in England and Wales. British Journal of Venereal Diseases, 54, 2-9.

Adler, M. W. (1978b). Diagnostic, treatment and reporting criteria for gonorrhoea in sexually transmitted diseases clinics in England and Wales. 1 : Diagnosis. British Journal of Venereal Diseases, 54, $10-14$.

Adler, M. W. (1978c). Diagnostic, treatment and reporting criteria for gonorrhoea in sexually transmitted diseases clinics in England and Wales. 2: Treatment and reporting criteria. British Journal of Venereal Diseases, 54, 15-23.
Adler, M. W. (1978d). Diagnostic, treatment, and reporting criteria for non-specific genital infection in sexually transmitted diseases clinics in England and Wales. 1: Diagnosis. British Journal of Venereal Diseases, 54, 422-427.

Adler, M. W. (1978e). Diagnostic, treatment, and reporting criteria for non-specific genital infection in sexually transmitted diseases clinics in England and Wales. 2: Treatment and reporting criteria. British Journal of Venereal Diseases, 54, 428-432.

Becker, H. and Schweisfurth, R. (1971). A medium for the diagnosis of vaginal candidiasis. Mykosen, 14, 127-130.

Belsey, E. M. and Adler, M. W. (1978). Current approach to the diagnosis of herpes genitalis. British Journal of Venereal Diseases, 54, 115-120.

Department of Health and Social Security (1976). Annual report of the Chief Medical Officer of Health. On the State of the Public Health. HMSO: London.

Eddie, D. A. (1968). The laboratory diagnosis of vaginal infections caused by Trichomonas and Candida species. Journal of Medical Microbiology, 1, 153-159.

Feinberg, J. G. and Whittington, M. J. (1957). A culture medium for Trichomonas vaginalis and species of Candida. Journal of Clinical Pathology, 10, 327-329.

Handsfield, H. H., Lipman, T. O., Harnisch, J. P., Tronca, E., and Holmes, K. K. (1974). Asymptomatic gonorrhoea in men: diagnosis, natural course, prevalence and significance. New England Journal of Medicine, 290, 117-123.

King, A. J. and Nicol, C. S. (1975). In Venereal Disease. Balliere Tindall and Cassell: London.

Madalena, J. C. and de Mattos, H. G. (1967). Use of metronidazole in alcoholism. Hospital (Rio de Janeiro), 71, (2), 481-488.

Morton, R. S. and Rashid, S. (1977). Candidal vaginitis: natural history, pre-disposing factors and prevention. Proceedings of the Royal Society of Medicine, 70, supplement 4, 3-6.

Portnoy, J., Mendelson, J., Clecner, B., and Heisler, M. (1974). Asymptomatic gonorrhoea in the male. Canadian Medical Association Journal, 110, 169-171.

Oriel, J. D. (1977). Clinical overview of candidal vaginitis. Proceedings of the Royal Society of Medicine, 70, supplement 4, 7-9.

Ridley, C. M. (1976). The Vulva. In Major Problems in Dermatology. Saunders: London.

Rothstein, E. and Clancy, D. D. (1969). Toxicity of disulfiram combined with metronidazole. New England Journal of Medicine, 280, 18, 1006.

Tsao, W. (1969). Trichomoniasis and gonorrhoea. British Medical Journal, 1, 642.

Watt, L. and Jennison, R. F. (1960). Incidence of Trichomonas vaginalis in marital partners. British Journal of Ve:iereal Diseases 36, 163-166. 